\title{
A IMPORTÂNCIA DA PROVA DO "ESTADO DE POSSE DE FILHO" PARA O RECONHECIMENTO DA PATERNIDADE SOCIOAFETIVO POST MORTEM E OS DIREITOS SUCESSÓRIOS, EM DEFESA DA DIGNIDADE HUMANA
}

\author{
Cleide Aparecida Gomes Rodrigues Fermentão1 \\ Gilberto Geraldino Filho2
}

\begin{abstract}
Resumo
A Filiação Socioafetiva é fruto do afeto, diferentemente da consanguinidade, que decorre do vínculo biológico. A Constituição Federal trouxe a plena igualdade entre os filhos, independentemente da origem da filiação. O Código Civil, em seu art. 1.593, parte final, encampou implicitamente a parentalidade socioafetiva. A posse do estado de filho caracteriza a filiação socioafetiva, podendo ser reconhecida após o falecimento do genitor, e assegura direitos sucessórios. Para isso, a prova de tal posse faz-se necessária. O reconhecimento de paternidade socioafetivo post mortem visa a proteção da dignidade e a igualdade do filho afetivo ao biológico.
\end{abstract}

Palavras-Chave: Reconhecimento; Filiação Socioafetiva; Post Mortem; Dignidade.

\section{THE IMPORTANCE OF THE PROOF OF THE "POSSESSION OF STATE OF SON" FOR THE RECOGNITION OF POST MORTEM SOCIOAFFECTIVE PATERNITY AND SUCCESSORY RIGHTS IN DEFENSE OF HUMAN DIGNITY}

\begin{abstract}
Socio-affective affiliation is the fruit of affection, unlike inbreeding, which results from the biological bond. The Federal Constitution brought the full equality between the children, regardless of the origin of the affiliation. The Civil Code, in its art. 1593, the final part implicitly implanted socio-affective parenting. The possession of the son state characterizes the socio-affective affiliation, being able to be recognized after the death of the parent, and assures succession rights. For this, proof of such possession is necessary. The recognition of post-mortem socio-affective paternity aims at the protection of the dignity and the equality of the affective child to the biological one.
\end{abstract}

Keywords: Recognition; Socio-affective Filiation; Post mortem; Dignity.

\section{1- INTRODUÇ̃̃̃O}

\footnotetext{
1 Doutora em direito das relações sociais pela UFPR-Universidade Federal do Paraná; mestrado e graduação pela UEM Universidade Estadual de Maringá. Professora do Programa de Mestrado em Direito e na graduação na UNICESUMAR - Centro Universitário de Maringá. Membro do Instituto dos advogados do Paraná. Advogada.

Mestrando em Ciências Jurídicas pela UNICESUMAR - Centro Universitário de Maringá. Especialista em Direito Público, com ênfase em Direito Constitucional, em nível de pós-graduação lato sensu, pela Universidade Potiguar. Especialista em Direito aplicado, em nível de pós-graduação lato sensu, pela Escola da Magistratura do Paraná. Graduado pela Universidade Estadual de Londrina (UEL). Promotor de Justiça do Ministério Público do Estado do Paraná.
}

Revista Brasileira de Direito Civil em Perspectiva | e-ISSN: 2526-0243 | Brasília | v. 3 | n. 1 | p. 113 - 127 | Jan/Jun. 2017. 
Com o advento da Constituição Federal de 1988, o Direito de Família evoluiu afastando-se do modelo patrimonialista e matrimonialista até então vigente. Em torno do princípio constitucional da dignidade da pessoa humana gravitaram outros importantes princípios na seara do Direito de Família, como o princípio da afetividade, solidariedade e igualdade da filiação. Hoje, independente de origem, há igualdade entre os filhos, com afastamento de odiosas discriminações. $\mathrm{O}$ afeto rege todas as relações familiares.

O presente artigo pretende analisar a possibilidade jurídica do reconhecimento da parentalidade socioafetiva post mortem e os seus efeitos no direito sucessório. O fundamento da pesquisa dar-se-á na análise da posse do estado de filho sob o alicerce dos princípios da dignidade da pessoa humana, afetividade e igualdade da filiação, as provas de tal posse e o entendimento dos Tribunais.

A análise buscará respostas para os seguintes questionamentos: Qual a importância da afetividade para as relações familiars? Há possibilidade do reconhecimento da parentalidade afetiva póstuma? O que os Tribunais exigem para a sua caracterização?

A presente pesquisa é importante para a ciência do direito em razão da análise da evolução do direito de família, tendo por essência a defesa da dignidade humana e da afetividade ao reconhecer a paternidade socioafetiva pos mortem e os direitos sucessórios. E o método a ser utilizado será o dedutivo, com pesquisa doutrinária, legislativa e jurisprudencial.

\section{PRINCÍPIO CONSTITUCIONAL DA AFETIVIDADE}

Com o advento da Constituição da República de 1988, o Direito de Família sofreu profundas alterações, adaptando-se às novas realidades sociais, afastando-se da origem patriarcal e matrimonialista da codificação civil de 1916. Foram consagrados, como valores maiores, a afetividade, solidariedade e a igualdade entre os filhos, todos em atendimento ao princípio da dignidade humana.

Como afirma Dias (2016, p. 24), a ordem constitucional elevou a dignidade da pessoa humana a fundamento da ordem jurídica. Houve opção expressa pela pessoa, ligando todos os institutos à realização de sua personalidade. Tal fenômeno provocou a despatrimonialização e a 


\section{A importância da prova do "estado de posse de filho" para o reconhecimento da paternidade socioafetivo post mortem e os direitos sucessórios, em defesa da dignidade humana}

personalização dos institutos jurídicos, de modo a colocar a pessoa humana no centro protetor do direito.

A diretriz constitucional de maior alcance no Direito Privado é a do princípio da dignidade da pessoa humana - um dos fundamentos da República, nos termos do art. $1^{\circ}$, inciso III, da Constituição. Tal princípio em sua abstratividade, veda a institucionalização de mecanismos ou de práticas injustas, que impliquem a discriminação ou a coisificação da pessoa humana. Esse princípio fundamenta a justice e a proteção da pessoa. Nader ( 2016, v. 5, p. 433),

A evolução das relações familiars no direito contemporâneo é fruto dos princípios constitucionais, e a afetividade tem norteado e fortalecido tais relações em relação à parentalidade. A origem biológica da família perdeu força diante do reconhecimento do afeto como vetor principal das relações familiares. Nas precisas palavras de Oliveira (2002, p. 242), "a família só tem sentido enquanto unida pelos laços de respeito, consideração, amor e afetividade".

Hironaka (1999) ressalta também que a verdade jurídica cedeu vez à imperiosa passagem e instalação da verdade da vida. E a verdade da vida está que a família muda o seu cerne fundamental, muda a razão de sua constituição, existência e sobrevida, mudam as pessoas que a compõem, pessoas estas que passam a ter a coragem de admitir que se casam principalmente por amor, pelo amor e enquanto houver amor. A família assim constituída independente da diversidade de sua gênese - pode ser mesmo aquele remanso de paz, ternura e respeito, lugar em que haverá, mais que em qualquer outro, para todos e para cada um de seus componentes, a enorme chance da realização de seus projetos de felicidade.

O amor como princípio da ratio aproxima os membros das famílias entre si, comungando dos mesmos valores, dos mesmos sonhos e das mesmas dificuldades. A família fruto do amor encontra respostas às angústias da vida, às intempéries dos dias, e nas lágrimas de dor e de emoção. O direito tem o mister de proteger a afetividade como defesa da dignidade da pessoa humana, pela paz que o amor alimenta a alma humana, e sustenta e norteia a família.

E conforme ensina Lobo (2004, p. 155), a realização da afetividade e da dignidade humana, no ambiente de convivência e solidariedade, são as funções básicas da família atuais. As antigas funções econômica, política religiosa e procracional desapareceram, ou 
desempenham papel secundário. Até mesmo a função procracional, com a secularização crescente do direito de família e a primazia atribuída ao afeto, deixou de ser sua finalidade precípua.

No contexto atual, a função principal da família é proporcionar a plena realização pessoal de seus membros, em atendimento a suas dignidades, e são admitidos novas formas de arranjos familiares outrora tidos como inconcebíveis. As relações familiares, atualmente, são afetivas, sendo a família composta por uma comunhão de afetos, antes de ser um instituto jurídico. O afeto é um sentimento que se traduz em fatos para o direito, fatos esses que se verificam na convivência social, originando a socioafetividade (Barboza, 2009).

O princípio da afetividade está implícito no princípio da dignidade humana porque estabelece a importância do amor na igualdade dos filhos, na igualdade dos cônjuges e companheiros, na paternidade responsável e no melhor interesse da criança e do adolescente. A Constituição Federal ao estabelecer que todas as pessoas são iguais perante a lei, fez cessar a dor daqueles filhos que mesmo adotados como tais eram tratados de forma diferente pela lei, assim como retirou a assimetria que havia entre os cônjuges e companheiros, e, o amor passou a ser considerado essencial para o desenvolvimento físicopsíquico da pessoa humana. $\mathrm{O}$ reconhecimento da paternidade socioafetivo é fruto de um novo olhar do direito, fortalecendo o amor entre os membros da família, e, considerando como tal aqueles que não são filhos biológicos, mas tendo vivido na posse de estado de filho, são reconhecimentos como filho com todos os direitos. Assim, provada a posse de estado de filho, mesmo após a morte a filiação sócio afetivo é reconhecida.

\section{PARENTESCO SOCIOAFETIVO}

O parentesco é natural ou civil, conforme resulte de consangüinidade ou outra origem (art. 1.593 do Código Civil), e se estrutura em linhas e graus, nos termos estabelecidos nos artigos 1591, 1.592, 1.594 e 1.595 do mesmo código). Nos dias atuais a doutrina e a jurisprudência têm entendido que o parentesco "natural", resultante da consanguinidade, é o parentesco biológico ou genético, e o "civil", resultante de "outra origem", é o socioafetivo, compreendendo a adoção e a filiação oriunda das técnicas de reprodução assistida heterólogas, vale dizer, naquelas em que haja participação de doador de material fecundante 


\title{
A importância da prova do "estado de posse de filho" para o reconhecimento da paternidade socioafetivo post mortem e os direitos sucessórios, em defesa da dignidade humana
}

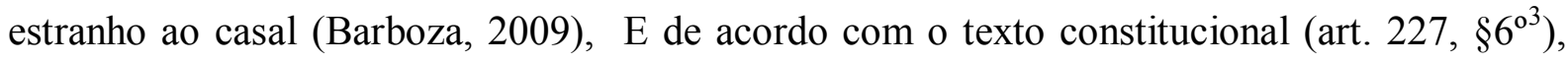
hoje não mais se admite qualquer discriminação quanto a origem do parentesco, seja biológico ou não.

Nas palavras de Chaves e Rosenvald (2014, p. 539),

\begin{abstract}
"A partir do Texto Maior de 5 de outubro, todos os filhos passaram a ter as mesmas prerrogativas, independentemente de sua origem ou da situação jurídica dos seus pais $\left(\mathrm{CF}\right.$, art. $\left.227, \S 6^{\circ}\right)$. Trata-se, sem dúvida, de normaprincípio paradigmática, servindo para eliminar todo e qualquer tipo de tratamento discriminatório (bastante comuns no sistema do Código Civil de 1916, que optou por conferir privilégios ao filho nascido de um casamento). Com isso, afastaram-se também do campo filiatório os privilégios concedidos a uma, ou outra, pessoa em razão da simples existência de casamento. Foram afastadas, em síntese apertada, as discriminações perpetradas contra os filhos de pessoas não casadas."
\end{abstract}

A mudança de paradigma se iniciou, principalmente, após a descoberta do DNA, quando a presunção de paternidade ("pater is est"), decorrente do casamento, foi cedendo lugar à investigação de paternidade biológica, realizada por meio de precisos exames de confrontação genética. Mas para a atual Constituição, a verdade genética não é suficiente para a caracterização da figura de pai ou mãe, estando a família contemporânea unida pela marca da afetividade e da solidariedade, sendo diferenciadas a figura de pai (afeto) da de genitor (provedor genético).

Para o atual Direito de Família, a verdade biológica remanesce de forma secundária, muitas vezes cedendo em face da paternidade socioafetiva estabelecida, principalmente nos casos de adoção de fato ("pai de criação") e "adoção à brasileira". O Código Civil, em seu art. $1.593^{4}$, encampou implicitamente a possibilidade do reconhecimento da filiação socioafetiva ao dispor que "o parentesco é natural ou civil, conforme resulte de consangüinidade ou outra origem.

Para o reconhecimento da paternidade socioafetiva, calcada na parte final do art. 1.593 do Código Civil, em atenção ao princípio constitucional da igualdade entre os filhos, a

\footnotetext{
3 Art. 227 [...] $\S 6^{\circ}$ Os filhos, havidos ou não da relação do casamento, ou por adoção, terão os mesmos direitos e qualificações, proibidas quaisquer designações discriminatórias relativas à filiação.

Art. 1.593. O parentesco é natural ou civil, conforme resulte de consanguinidade ou outra origem.
}

Revista Brasileira de Direito Civil em Perspectiva | e-ISSN: 2526-0243 | Brasília | v. 3 | n. 1 | p. 113 - 127 | Jan/Jun. 2017. 
doutrina e a jurisprudência pátria têm exigido a presença da chamada "posse do estado de filho".

Como bem observa Boeira (1999, p. 90),

\begin{abstract}
"a posse do estado de filho é uma relação afetiva, íntima e duradoura, caracterizada pela reputação diante de terceiros como se filho fosse, e pelo tratamento existente na relação paterno-filial, em que há o chamamento de filho e a aceitação do chamamento de pai".
\end{abstract}

É possível dizer que a posse de estado de filho é estar como filho, ser criado como filho, ser chamado e educado como tal, e o tratamento é de pai e de filho. Essa relação de pai e filho precisa ser pública, diante de toda a família e da sociedade. A convivência e o tratamento de pai e filho presume o amor existente entre ambos.

Dias (2016, p. 277) traz os requisitos que a doutrina elenca para o reconhecimento da posse do estado de filho: (a) tractatus, quando o filho é tratado como tal, criado, educado e apresentado como filho pelo pai e pela mãe; (b) nominatio, quando o filho usa o nome da família e assim se apresenta; e (c) reputatio, quando o filho é conhecido pela opinião pública como pertencente à família de seus pais. Confere-se à aparência os efeitos de verossimilhança que o direito considera satisfatória.

A aferição da realidade socioafetiva se dá, portanto, pela constatação de que ser pai ou mãe, não se pauta apenas no vínculo genético com a criança, mas naquela pessoa que cria, educa, dá amor, carinho, dignidade e condição de vida, realmente exercendo a função de pai ou de mãe levando em consideração o melhor interesse da criança.

A paternidade socioafetiva já foi objeto de debate pela doutrina, com enunciados aprovados nas Jornadas de Direito Civil do Conselho da Justiça Federal ${ }^{5}$, bem como foi objeto de enunciado aprovado pelo Instituto Brasileiro de Direito de Família (IBDFAM) ${ }^{6}$. Por sua vez a Lei n ${ }^{\circ} 11.924$, de 17 de abril de 2009, também chamada Lei Clodovil Hernandes, ao

\footnotetext{
5 Enunciado n. 103: O Código Civil reconhece, no art. 1.593, outras espécies de parentesco civil além daquele decorrente da adoção, acolhendo, assim, a noção de que há também parentesco civil no vínculo parental proveniente quer das técnicas de reprodução assistida heteróloga relativamente ao pai (ou mãe) que não contribuiu com seu material fecundante, quer da paternidade socioafetiva, fundada na posse do estado de filho. Enunciado n. 519: O reconhecimento judicial do vínculo de parentesco em virtude de socioafetividade deve ocorrer a partir da relação entre pai(s) e filho(s), com base na posse do estado de filho, para que produza efeitos pessoais e patrimoniais.

Enunciado $\mathrm{n}^{\circ}$ 7: A posse de estado de filho pode constituir a paternidade e maternidade.
} 


\section{A importância da prova do "estado de posse de filho" para o reconhecimento da paternidade socioafetivo post mortem e os direitos sucessórios, em defesa da dignidade humana}

inserir o $§ 8^{\circ}$ no art. 57 na Lei de Registros Públicos ${ }^{7}$ admitiu, ainda que de forma implícita, a existência do parentesco socioafetivo, ao permitir ao enteado ou enteada acrescer ao seu nome o apelido de seu padrasto ou madrasta.

Para Cassettari (2017), "a filiação socioafetiva pode decorrer da adoção de fato (filho de criação), adoção à brasileira, filhos havidos fora do casamento, fecundação artificial heteróloga e filhos decorrentes da relação de padrastio e madrastio." O filho de criação é uma das espécies de filiação socioafetiva. Essa modalidade de filiação ocorre nos casos em que, mesmo não existindo nenhum vínculo jurídico - por meio da adoção - ou biológico, os pais criam uma pessoa por mera opção. (Nogueira, 2001)

A "adoção a brasileira" é uma ação pelo qual uma pessoa registra o filho de outrem como se seu fosse, sendo, porém, uma adoção sem o devido processo legal, é uma forma de reconhecimento da paternidade socioafetiva em detrimento da biológica. Tal conduta é capitulada como crime pelo Código Penal (art. 242).

Os filhos havidos fora do casamento, muitas vezes, acabam sendo criados pelo cônjuge traído, já que o parceiro que teve o filho fora do casamento, em alguns casos, o leva para morar com sua família, e com isso acaba sendo formada uma socioafetividade (Cassettari, 2017). E, o reconhecimento da paternidade na fecundação artificial heteróloga, que é aquela feita com utilização de esperma pertencente a terceiro, com consentimento do marido, traduz verdadeira forma de filiação socioafetiva.

E como assevera Madaleno (2013), a filiação socioafetiva pode ser admitida com base nos seguintes artigos do Código Civil: (a) art. 1.593, que diz que o parentesco é natural ou civil, conforme resulte de consanguinidade ou outra origem. Esta outra origem de parentesco seria justamente a sociológica (afetiva, socioafetiva, social, eudemonista); (b) art. 1.596, em que é reafirmada a igualdade entre a filiação (art. 227, § $6^{\circ}$, da Constituição Federal de 1988); (c) art. 1.597, $\mathrm{V}$, pois o reconhecimento voluntário da paternidade na inseminação artificial heteróloga não é de filho biológico, e sim de filho socioafetivo, já que o material genético não é do(s) pai(s), mas, sim, de terceiro(s); (d) art. 1.603, visto que, enquanto a família biológica navega na cavidade sanguínea, a família afetiva transcende os mares do sangue, conectando o ideal da paternidade e da maternidade responsável, hasteando o véu impenetrável que encobre as relações sociológicas, regozijando-se com o

\footnotetext{
7 Art. $57[\ldots] \S 8 \underline{0}$ O enteado ou a enteada, havendo motivo ponderável e na forma dos $\S \S 2 \underline{0}$ e $7 \underline{0}$ deste artigo, poderá requerer ao juiz competente que, no registro de nascimento, seja averbado o nome de família de seu padrasto ou de sua madrasta, desde que haja expressa concordância destes, sem prejuízo de seus apelidos de família.
} 
nascimento emocional e espiritual do filho, edificando a família pelo cordão umbilical do amor, do afeto, do desvelo, do coração e da emoção, (re)velando o mistério insondável da filiação, engendrando um verdadeiro reconhecimento do estado de filho afetivo; (e) art. 1.605, II, em que filiação é provada por presunções - posse de estado de filho (estado de filho afetivo).

Mister salientar que em muitos casos o vínculo socioafetivo prevalece sobre o biológico, no caso de crianças, pela observância do princípio do melhor interesse da criança. E, nada impede a concomitância do vínculo socioafetivo com o biológico, dando origem à chamada multiparentalidade. Quanto a prevalência da paternidade socioafetiva sobre a biológica, foi reconhecida repercussão geral, pelo Supremo Tribunal Federal, no Agravo em Recurso Extraordinário n. 692186 RG - Paraíba, em 29 de novembro de 2012.

O reconhecimento da filiação socioafetiva se dá, via de regra, pela Ação Declaratória de Paternidade Afetiva, nada impedindo, todavia, seu reconhecimento por meio de escritura pública (Cassettari, 2017). E, também a filiação socioafetiva pode ser declarada por sentença mesmo se movida a ação após a morte do pai afetivo.

\section{DIREITOS SUCESSÓRIOS DO FILHO SOCIOAFETIVO}

O reconhecimento da paternidade ou da maternidade socioafetivo produz todos os efeitos pessoais e patrimoniais que lhe são inerentes à filiação biológica. O vínculo de filiação afetiva, que se legitima no interesse do filho, gera o parentesco afetivo para todos os fins de direito, nos limites da lei civil. Se menor, com fundamento no princípio do melhor interesse da criança e do adolescente; se maior, por força do princípio da dignidade da pessoa humana, que não admite um parentesco restrito. O princípio da solidariedade se aplica a ambos os casos. Fermentão (2016) lembra ainda que, uma vez reconhecida a paternidade socioafetiva, que acontece se provado a "posse do estado de filho", o filho de criação tem reconhecido todos os direitos inerentes à filiação, como o direito ao nome, aos alimentos, à herança, bem como previdenciários.

O direito à herança é um direito fundamental do cidadão, previsto no artigo $5^{\circ}$, inciso XXX, da Constituição Federal. Tartuce (2014, p. 39) conceitua a herança como sendo o conjunto de bens, positivos e negativos, formado com o falecimento do de cujus, englobando também as dívidas do morto. 


\section{A importância da prova do "estado de posse de filho" para o reconhecimento da paternidade socioafetivo post mortem e os direitos sucessórios, em defesa da dignidade humana}

Segundo o art. 1.798 do Código Civil, só estão legitimadas a suceder as pessoas nascidas ou já concebidas no momento da abertura da sucessão. Tratando-se de sucessão legítima, apenas as pessoas nascidas ou já concebidas no momento da morte do de cujus é que têm vocação para serem herdeiros ou legatários. Na sucessão testamentária, todavia, admitese como herdeiro pessoa ainda não concebida, quando se tratar de filho de pessoa expressamente designada pelo testador ou de substituição fiduciária (fideicomisso). Trata-se do denominado "princípio da coexistência": o sucessor e o de cujus devem coexistir no momento da abertura da sucessão, para que ocorra a transmissão da herança (Gagliano, Pamplona, 2014, p. 59).

Excepciona a esta regra é o caso de filiação post mortem. Neste caso, há uma presunção legal de que o filho nasceu na constância do casamento. Desta forma, ainda que não concebido no momento do falecimento do pai, o filho concebido por inseminação artificial após a morte do genitor tem legitimidade para herdar (art. 1.597, III, do Código Civil).

A filiação socioafetiva post mortem, acontece em atendimento aos princípios da igualdade da filiação e da dignidade humana. Ainda que somente se reconheça o vínculo socioafetivo após o falecimento do pai afetivo, é certo que o filho já ostentava tal condição quando do óbito do genitor afetivo, razão pela qual a sentença será declaratória, retroagindo seus efeitos à data do início da convivência afetiva comprovada, assegurando-se direitos hereditários ao filho socioafetivo. O herdeiro poderá reivindicar seus direitos no próprio inventário, caso ainda esteja em trâmite, ocasião em que o juiz do inventário poderá suspender o processo até que resolva definitivamente a demanda em que se discute a paternidade socioafetivo, com base no art. 313, inciso V, alínea "a", do Código de Processo Civil.

Caso o inventário já esteja findo, o herdeiro socioafetivo poderá demandar seus direitos hereditários por meio de Ação Declaratória de reconhecimento de Paternidade/Maternidade Socioafetiva pos mortem, cumulada com Ação de petição de herança, com base nos arts. 1.593 e 1.824 do Código Civil. É certo que o reconhecimento do estado de filiação constitui direito personalíssimo, indisponível e imprescritível, que pode ser exercitado, portanto, sem qualquer restrição, em face dos pais ou seus herdeiros.

O Código Civil foi omisso quanto ao prazo prescricional para o exercício da Petição de Herança. Deste modo, aplica-se, a regra subsidiária do artigo 205, que estabelece que a 
prescrição ocorre em dez anos, quando a lei não lhe haja fixado prazo menor. Se a morte se deu na vigência do Código Civil de 1916, o prazo prescricional será de 20 anos (art. 177 do $\mathrm{CC} / 16)$. A controvérsia se estabelece quanto ao termo inicial de sua contagem, ou seja, o dies a quo desse prazo. Em regra geral, o prazo decenal conta-se a partir da abertura da sucessão, ou seja, do falecimento do autor da herança.

$\mathrm{Na}$ hipótese em que a filiação é reconhecida após o óbito do genitor, prevalece o entendimento de que o prazo não se inicia da abertura da sucessão, mas sim do trânsito em julgado da decisão que reconheceu a parentalidade socioafetiva ${ }^{8}$.

\section{A QUESTÃO DA PROVA DA PARENTALIDADE SOCIOAFETIVA POST MORTEM NOS TRIBUNAIS}

Os Tribunais brasileiros, de forma geral, tem sido rigorosos na aferição da posse do estado de filho, reconhecendo a parentalidade socioafetiva somente quando cabalmente comprovada tal posse nos autos. O Superior Tribunal de Justiça, em julgado de 2014, afastou o reconhecimento da parentalidade socioafetiva decorrente da adoção de fato, mas ressaltou, com precisão, os requisitos necessários à configuração do instituto ${ }^{9}$.

8 Neste sentido, decidiu o Tribunal do Mato Grosso, em julgado de 2016: RECURSO DE APELAÇÃO CÍVEL AÇÃO DE RECONHECIMENTO DE PATERNIDADE SOCIOAFETIVA "POS MORTEM" - PRELIMINAR DE PRESCRIÇÃO dA PETIÇÃO DE HERANÇA - REJEITAdA - AUSÊNCIA DE PROVA DE FILIAÇÃO SOCIOAFETIVA - PROVA INCONTESTE DE QUE O APELADO NÃO É O PAI BIOLÓGICO DA APELANTE AUSÊNCIA DE PROVA DE VONTADE ESPONTÂNEA DO "DE CUJUS" EM RELAÇÃO AO ESTADO DE FILHO - AUSÊNCIA DE RECIPROCIDADE QUANTO AO TRATAMENTO AFETIVO PELO FALECIDO DECISÃO MANTIDA - APELO DESPROVIDO - O prazo prescricional para o ajuizamento de ação de petição de herança é o previsto no artigo 205 do Código Civil . No entanto, ele não começa a fluir enquanto não transitado em julgado a sentença proferida na ação de reconhecimento de paternidade. Existindo prova de que o Autor/Apelante não é filho biológico, é possível declarar a paternidade socioafetiva, desde que haja demonstração cabal da vontade do "de cujus" quanto ao reconhecimento (posse do estado de filho) do autor, bem como dos demais elementos que demonstrem afeto necessário à declaração de vínculo familiar. (TJMT - Ap 136180/2015 - Rel. Des. Sebastião Barbosa Farias - DJe 04.03.2016 - p. 80)

9 AÇÃO DECLARATÓRIA DE MATERNIDADE - RECONHECIMENTO POST MORTEM PRETENSÃO - "Recurso especial. Ação declaratória de maternidade c/c petição de herança. Pretensão de reconhecimento post mortem de maternidade socioafetiva, com a manutenção, em seu assento de nascimento, da mãe registral. Alegação de que a mãe registral e a apontada mãe socioafetiva procederam, em conjunto, à denominada 'adoção à brasileira' da demandante, quando esta possuía apenas dez meses de vida. [...] O estabelecimento da filiação socioafetiva requer a vontade clara e inequívoca da pretensa mãe socioafetiva, ao despender expressões de afeto, de ser reconhecida, voluntariamente,

Revista Brasileira de Direito Civil em Perspectiva | e-ISSN: 2526-0243 | Brasília | v. 3 | n. 1 | p. 113 - 127 | Jan/Jun. 2017. 


\section{A importância da prova do "estado de posse \\ de filho" para o reconhecimento da paternidade socioafetivo post mortem e os direitos sucessórios, em defesa da dignidade humana}

Por sua vez, o Tribunal do Rio de Janeiro, em demanda que objetivava o reconhecimento de maternidade post mortem, decidiu que, na relação de padrastio ou madrastio, a mera existência de carinho e afeição não são suficientes para caracterizar a filiação socioafetiva, sendo necessária a intenção inequívoca do padrasto ou madrasta de assumir, de forma incondicional, a paternidade ou maternidade, "direcionada à integração definitiva do novo ser ao círculo familiar" ${ }^{\prime 10}$.

O Tribunal de Justiça do Rio Grande do Sul também afastou o reconhecimento da paternidade socioafetiva do filho de criação no ano de 2015, ao reconhecer a necessidade de manifestação inequívoca do de cujus de receber o requerente como filho, quando em vida, ${ }^{11}$.

como tal, bem como a configuração da denominada 'posse de estado de filho', que, naturalmente, deve apresentar-se de forma sólida e duradoura. [...], embora se afigure possível o reconhecimento do estado de filiação, estribada no estabelecimento de vínculo socioafetivo, inclusive em hipóteses em que os pais formem um casal homossexual, não restou demonstrado nos autos a intenção da pretensa mãe socioafetiva em, também, adotá-la, sendo certo, ainda, que a mãe registral e a suposta mãe socioafetiva não constituíram um casal homoafetivo, tanto que esta última, posteriormente, casou-se com o primeiro demandado. 2. A constituição da filiação socioafetiva perpassa, necessariamente, pela vontade e, mesmo, pela voluntariedade do apontado pai/mãe, ao despender afeto, de ser reconhecido juridicamente como tal. É dizer: as manifestações de afeto e carinho por parte de pessoa próxima à criança somente terão o condão de convolarem-se numa relação de filiação, se, além da caracterização do estado de posse de filho, houver, por parte daquele que despende o afeto, clara e inequívoca intenção de ser concebido como pai/mãe daquela criança. [...] Efetivamente, o que se está em discussão, e pende de demonstração, é se houve ou não o estabelecimento de filiação socioafetiva entre a demandante e a apontada mãe socioafetiva, devendo-se perquirir, para tanto: i) a vontade clara e inequívoca da pretensa mãe socioafetiva, ao despender expressões de afeto, de ser reconhecida, voluntariamente, como mãe da autora; II) a configuração da denominada 'posse de estado de filho', que, naturalmente, deve apresentar-se de forma sólida e duradoura. Todavia, em remanescendo dúvidas quanto à verificação dos referidos requisitos (em especial do primeiro, apontado pelo Tribunal de origem), após concedida oportunidade à parte de demonstrar os fatos alegados, há que se afastar, peremptoriamente, a configuração da filiação socioafetiva. É de se ressaltar, inclusive, que a robustez da prova, na hipótese dos autos, há de ser ainda mais contundente, a considerar que o pretendido reconhecimento de filiação socioafetiva refere-se à pessoa já falecida. [...] Em atenção às novas estruturas familiares, baseadas no princípio da afetividade jurídica (a permitir, em última análise, a realização do indivíduo como consectário da dignidade da pessoa humana), a coexistência de relações filiais ou a denominada multiplicidade parental, compreendida como expressão da realidade social, não pode passar despercebida pelo direito. [...] (STJ - REsp 1.328.380 - (2011/02338210) - $3^{\mathrm{a}}$ T. - Rel. Min. Marco Aurélio Bellizze - DJe 03.11.2014 - p. 1399)

10 TJRJ - Ap 0093734-12.2014.8.19.0001 - 10ª C.Cív. - Rel. Celso Luiz de Matos Peres - DJe 18.04.2016

11 APELAÇÃO CÍVEL - PEDIDO DE RECONHECIMENTO PÓSTUMO DE FILIAÇÃO SOCIOAFETIVA, CUMULADO COM PETIÇÃO DE HERANÇA E RETIFICAÇÃO DO REGISTRO CIVIL - FILHO DE CRIAÇÃO - IMPROCEDÊNCIA - Caso em que o falecido acolheu o apelante em sua casa, prestando orientação moral e sustento material, sem, contudo, manifestar vontade inequívoca de adotar. Testemunhas que apenas confirmam a relação, aparentemente, paterno-filial entre requerente e de cujus, que nada mais demonstram a prestação de auxílio fraternal e

Revista Brasileira de Direito Civil em Perspectiva | e-ISSN: 2526-0243 | Brasília | v. 3 | n. 1 | p. 113 - 127 | Jan/Jun. 2017. 
Tal cautela, como se percebe, se deve às repercussões econômicas do reconhecimento da paternidade socioafetiva, em especial diante do direito à herança, em especial quando ausentes outros herdeiros sucessíveis, que possam se opor à pretensão. Por outro lado, o Tribunal de Justiça do Estado de Goiás, em julgado de 2014, reconheceu a paternidade socioafetiva post mortem, pela comprovação da existência da "posse do estado de filho", afastando alegações de interesses patrimoniais ${ }^{12}$.

Em sentido oposto, o Tribunal de Minas Gerais, no ano de 2009, reconheceu a existência de interesses patrimoniais da pretensa filha socioafetiva e afastou o reconhecimento da paternidade socioafetiva post mortem $^{13}$. Assim, a questão probatória se sobrepõe à questão jurídica, na medida em que amplamente reconhecida, tanto em solo doutrinário, como jurisprudencial, a possibilidade da existência da parentalidade socioafetiva, à luz dos princípios da afetividade e da igualdade da filiação, cingindo-se o debate à efetiva comprovação, ou não, da posse do estado de filho.

amparo moral, característicos da relação de "pai de criação", muito típica do interior do Estado, mas que não tem a força para constituir vínculo socioafetivo de filiação. Precedentes jurisprudenciais. NEGARAM PROVIMENTO. (TJRS - AC 70063212617 - $8^{a}$ C.Cív. - Rel. José Pedro de Oliveira Eckert - J. 23.04.2015

12 EMBARGOS DE DECLARAÇÃO EM APELAÇÃO CÍVEL - AÇÃO DE INVESTIGAÇÃO DE PATERNIDADE C/C RESTITUIÇÃO DE HERANÇA - PATERNIDADE SOCIOAFETIVA RECONHECIDA EFEITOS JURÍDICOS - DIREITO À HERANÇA - AUSÊNCIA DE INTERESSES MERAMENTE PATRIMONIAIS - OMISSÃO - NÃO OCORRÊNCIA - 1- O reconhecimento da paternidade socioafetiva tem como efeito jurídico o direito à herança entre pais, filhos e parentes sociológicos, não podendo ser desconstituída uma situação de estado de filiação perpetrada durante longos anos, a mera alegação de interesses meramente patrimoniais da interessada no reconhecimento, quando não comprovada tal intenção. 2- A matéria já submetida previamente a julgamento não pode ser rediscutida em embargos de declaração subsequente, sem qualquer elemento novo, notadamente quando não resta demonstrada a omissão alegada e os aclaratórios visam tão somente a modificação da questão de fundo da causa. Precedentes do STJ. Embargos de declaração conhecidos e rejeitados. (TJGO - EDcl 200591772248 - $3^{\text {a }}$ C.Cív. - Rel. Des. Itamar de Lima - DJe 20.05.2014 - p. 277)

13 AÇÃO DE REIVINDICAÇÃO DE PATERNIDADE SOCIOAFETIVA "POS MORTEM" - INTERESSES PURAMENTE FINANCEIROS - AFASTAMENTO DO JUÍZO ÉTICO E JUSTO - IMPROCEDÊNCIA DO PEDIDO - Admitir que o Poder Judiciário supra a vontade da pessoa que foi criada por um casal que, movido pela solidariedade, abrigou o jovem em sua família e passou a criá-lo e educá-lo, para mais tarde receber um prêmio, de pai e mãe socioafetivos, gerando efeitos na esfera do Direito Sucessório, seria desvirtuar toda a interpretação conferida ao instituto da paternidade socioafetiva. Isso porque a busca de uma tardia reivindicação parental, com interesses puramente financeiros, significaria o afastamento de um juízo ético e justo proposto por nosso ordenamento jurídico. [...] (TJMG - AC 1.0382.06.064486-3/001 - $1^{\text {a }}$ C.Cív. - Rel. Alberto Vilas Boas - J. 30.01.2009)

Revista Brasileira de Direito Civil em Perspectiva | e-ISSN: 2526-0243 | Brasília | v. 3 | n. 1 | p. 113 - 127 | Jan/Jun. 2017. 


\section{CONCLUSÃO.}

O Direito de Família sofreu profundas alterações com o advento da Constituição Federal de 1988, afastando-se da origem patriarcal e matrimonialista da codificação civil de 1916. Foram consagrados, como valores maiores, a afetividade, solidariedade e a igualdade entre os filhos, todos em atendimento ao princípio da dignidade humana. As novas realidades sociais levaram à evolução do direito de família, consagrando o afeto como essencial na formação físicopsíquico dos membros da família, tendo como fundamento o princípio da dignidade humana.

A evolução das relações familiars no direito contemporâneo é fruto dos princípios constitucionais, e a afetividade tem norteado e fortalecido tais relações em relação à parentalidade. A origem biológica da família perdeu força diante do reconhecimento do afeto como vetor principal das relações familiares

A parentalidade socioafetiva é uma realidade nos dias atuais, amplamente reconhecida pelo Direito, apesar da ausência de regulamentação específica, decorrendo dos princípios constitucionais da dignidade da pessoa humana, afetividade e igualdade da filiação. Não são admitidas discriminações de qualquer sorte, e o afeto é o elemento caracterizador da entidade familiar, independente da forma que o arranjo familiar se materialize.

O amor é o laço que aproxima os membros das famílias entre si, comungando dos mesmos valores. $\mathrm{O}$ direito tem o mister de proteger a afetividade como defesa da dignidade da pessoa humana, pela paz que o amor alimenta a alma humana e sustenta e norteia a família.

O princípio da afetividade está implícito no princípio da dignidade humana porque estabelece a importância do amor na igualdade dos filhos, na igualdade dos cônjuges e companheiros, na paternidade responsável e no melhor interesse da criança e do adolescente.

O reconhecimento da paternidade socioafetivo é fruto de um novo olhar do direito, fortalecendo o amor entre os membros da família, e, considerando como tal aqueles que não são filhos biológicos, mas viveram na posse de estado de filho. São reconhecimentos como filho com todos os direitos, se provado a posse de estado de filho.

A posse de estado de filho pode ser entendida como ser criado como filho, ser chamado e educado como tal, e o tratamento é de pai e de filho. Essa relação de pai e filho precisa ser pública, diante de toda a família e da sociedade. 
O reconhecimento da paternidade ou da maternidade afetiva produz todos os efeitos pessoais e patrimoniais que lhe são inerentes à filiação biológica. $O$ vínculo de filiação afetiva, que se legitima no interesse do filho, gera o parentesco afetivo para todos os fins de direito, nos limites da lei civil

Reconhece-se ao filho socioafetivo, que detém a posse do estado de filho (tratamento, nome e fama) todos os direitos inerentes à filiação, dentre eles o direito a alimentos e herança. Para tal reconhecimento faz-se preciso provar a posse de estado de filho. A ação de reconhecimento de paternidade é imprescritível, podendo ser exercitada a qualquer tempo. Assim, surge a possibilidade do reconhecimento da parentalidade socioafetiva após a morte do pai ou mãe afetivas (post mortem).

Os Tribunais têm debatido, frequentemente, o tema da parentalidade socioafetiva, não pendendo discussão quanto a existência ou não de tal forma de filiação, mas sim quanto à efetiva caracterização da posse do estado de filho, que precisa ser provada, para não deixar dúvidas sobre a relação afetiva de pai e filho, que se consideram e se tratam como tal diante da sociedade.

\section{REFERÊNCIAS.}

BARBOZA, Heloisa Helena. Efeitos jurídicos do parentesco socioafetivo. Revista Brasileira de Direito das Famílias e Sucessões. Porto Alegre: Magister, v. 9, p. 29, abr./maio 2009.

BOEIRA, José Bernardo Ramos. Investigação de paternidade: posse de estado de filho. Porto Alegre: Livraria do Advogado, 1999.

BRASIL. Lei Federal n. 6.015, de 31 de dezembro de 1973. Disponível em $<$ http://www.planalto.gov.br/ccivil_03/leis/L6015consolidado.htm>

BRASIL. Constituição Federal, promulgada em 5 de outubro de 1988. Disponível em <http://www.planalto.gov.br/ccivil_03/constituicao/constituicao.htm>

BRASIL. Lei Federal n. 10.406, de 10 de janeiro de 2002. Disponível em <http://www.planalto.gov.br/ccivil_03/leis/L6015consolidado.htm>

DIAS, Maria Berenice. Manual de Direito das Famílias. 11 a Ed., São Paulo: RT, 2016, v. ebook. 


\section{A importância da prova do "estado de posse \\ de filho" para o reconhecimento da paternidade socioafetivo post mortem e os direitos sucessórios, em defesa da dignidade humana}

FERMENTÃO, Cleide Aparecida Gomes Rodrigues. O Reconhecimento da Filiação Socioafetivo Post Mortem com Fundamento nos Princípios da Igualdade e da Dignidade Humana. In: XXV Congresso Nacional do Conpedi, 2016, Curitiba. Anais. Disponível em:

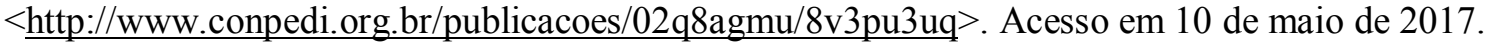

GAGLIANO. Pablo Stolze. PAMPLONA FILHO, Rodolfo. Novo Curso de Direito Civil. V. 7, $4^{a}$ Ed., São Paulo: Saraiva, 2014.

HIRONAKA, Giselda Fernandes Novaes. Família e casamento em evolução. Revista Brasileira de Direito de Família. Porto Alegre: Síntese, IBDFAM, v. 1, n. 1, p. 17, abr.jun. 1999.

LÔBO, Paulo Luiz Netto. A repersonalização das relações de família. Revista Brasileira de Direito de Familia. Porto Alegre: Síntese, IBDFAM, v. 6, n. 24, p. 155, jun./jul. 2004.

Direito Civil: Famílias. $4^{a}$ Ed., São Paulo: Saraiva, 2011.

MADALENO, Rolf Hanssen. Curso de direito de família. 5. ed. Rio de Janeiro: Forense, 2013.

NADER, Paulo. Curso de Direito Civil: Família. $7^{\text {a }}$ Ed. Vol. V. São Paulo: Forense, 2016.

NOGUEIRA, Jacqueline Filgueras. A filiação que se constrói: o reconhecimento do afeto como valor jurídico. São Paulo: Memória Jurídica Editora, 2001.

OLIVEIRA, José Sebastião de. Fundamentos constitucionais do Direito de Família. São Paulo: Revista dos Tribunais, 2002.

TARTUCE. Flávio. Direito Civil: Sucessões. $8^{a}$ Ed., São Paulo, Método, 2015. 